Persistence and Visibility of Group Faultlines: A Theoretical Model of the Effect of Group Culture and Team Identity on the Group Faultlines-Organizational Conflict

\title{
Link
}

Katerina Bezrukova

The Wharton School

University of Pennsylvania

Philadelphia, PA 19104-6370

Tel: (215) 573-5726

Fax: 215-898-0401

E-mail: bezrukov@wharton.upenn.edu

\author{
Karen A. Jehn \\ The Wharton School \\ University of Pennsylvania \\ Philadelphia, PA 19104-6370 \\ Tel: 215-898-7722 \\ Fax: 215-898-0401 \\ E-Mail: jehn@wharton.upenn.edu \\ Madhan Gounder \\ The Wharton School \\ University of Pennsylvania \\ Philadelphia, PA 19104-6370 \\ Tel: (215) 573-5726 \\ Fax: 215-898-0401 \\ E-mail: mgounder@wharton.upenn.edu
}

January, 2002 


\title{
Persistence and Visibility of Group Faultlines: A Theoretical Model of the Effect of Group Culture and Team Identity on the Group Faultlines-Organizational Conflict Link
}

\begin{abstract}
We expand the group faultline theory by taking into account the relative importance of various demographics within the group that can trigger the formation of strong group faultlines. We draw on group faultline theory (Lau \& Murnighan, 1998), social identity and categorization theories (Turner \& Tajfel, 1986), social dominance theory (Sidanius \& Pratto, 1999), and evolutionary psychology (Kurzban \& Leary, 2001) to predict how group faultlines affect conflict. We propose that the visible demographic characteristics (age, race, and gender) will be more influential than the non-visible (education, tenure, and function) in determining the interaction patterns within the group (Thatcher \& Jehn, 1998). We use the persistence argument from evolutionary psychological theory to further examine the relative importance of the demographics within the subgroups of non-visible and visible characteristics (Kurzban \& Leary, 2001). Persistency is defined as the length of time a certain characteristic has been incorporated into society and, based on evolutionary psychology, we propose that gender is more influential than race because gender differences appeared earlier in human society than race differences (Kurzban, Tooby, \& Cosmides, 2001). Similarly, we view tenure as more influential than education and function because it can be viewed as a manifestation of experience, which has long been valued in human society. We propose that models where we adjust for the relative influence of demographic characteristics based on our theory will have a better predictive caliber than when all characteristics are weighted equally. We also consider the moderating effects of group culture and team identity on the relationship between group faultlines and conflict. In particular, group culture and team identity will either inflate or deflate the potency of each demographic characteristic on conflict. That is, group faultlines will have less impact on conflict when there is a strong group culture strong team identity. Specifically in this case we examine an organizational culture focused on change.
\end{abstract}

Key words: group faultlines, group culture, team identity, and organizational conflict 


\section{Persistence and Visibility of Group Faultlines: A Theoretical Model of the Effect of Group Culture and Team Identity on the Group Faultlines-Organizational Conflict Link}

\section{Introduction}

We draw on group faultline theory (Lau and Murnighan 1998), social identity and categorization theories (Turner and Tajfel 1986), social dominance theory (Sidanius \& Pratto, 1999), and evolutionary psychology (Kurzban and Leary 2001) to predict how certain demographic characteristics contribute to the development of group faultlines. We define group faultlines as hypothetical dividing lines that split a group into subgroups based on the demographic characteristics of group members. We consider six demographic characteristics: age, gender, race, tenure with the company, level of education, and functional background in our analysis. We chose these variables based on the previous research on group diversity that showed these variables were potentially relevant for self-categorization and had significant results in assessing relational effects (Tsui, Egan, \& O’Reilly, 1992). Past research has always treated these six variables equally with respect to their potential impact on group processes and performance outcomes. This approach, however, is inherently simplistic, limited, and can not fully describe the nature of group composition. A more sophisticated conceptualization of group composition is needed. In this paper, we refine the demographic variables by examining group composition with respect to visibility and the persistence of the demographic characteristics over time within subgroups separated by visible versus nonvisible characteristics.

Social dominance theory suggests that human beings naturally form hierarchical groupings that represent a hierarchical ordering of groups according to their relative position in a larger system of groups (Sidanius \& Pratto, 1999). Furthermore, the researchers suggest that group members (in our case, subgroup members) share a schema that cognitively constructs other out-group members in a hierarchy by agreeing what groups are to be kept at a greater distance than others (Mullick \& Hraba, 2001). For example, subjects in the Netherlands, the former Soviet Union, Pakistan, and the United 
States hold social-distance hierarchies about ethnic groups in their own countries (Hagendoorn, Drogendijk, Tumanov, \& Hraba, 1998; Mullick \& Hraba, 2001). Similarly, we believe that all demographic characteristics can be viewed with respect to their relative importance constructed in a people's cognitive hierarchical schema. This hierarchy is bifunctional and reflects the relative importance/distances of categories within a certain characteristic (for ex. white group member is closer to Asian than to black) as well as the relative importance across characteristics (for ex. gender is more influential than race). We propose that two factors, visibility (or accessibility) of characteristics and their persistence over time might determine the importance of certain demographic characteristics in forming group faultlines. Specifically, we use the argument that visible characteristics (age, race, and gender) are easily observable and hence, are more accessible than non-visible characteristics (education, tenure, and function) (Tsui, Egan, \& O'Reilly, 1992). We further draw on the theory of group diversity profiles and categorization processes in bicultural organizational teams (Thatcher \& Jehn, 1998) to predict that the visible demographic characteristics will be more influential than the non-visible in determining the interaction patterns within the group that lead to the formation of group faultlines.

We use the persistence argument from evolutionary psychological theory to further examine the relative importance of the demographics within the subgroups of non-visible and visible characteristics (Kurzban \& Leary, 2001). In particular, we use the argument that evolutionary older characteristics emerged as a greater source of potential influence within human societies prior to younger characteristics, and thus, carry more weight. We propose that, for example, gender will be more influential than race based on this reasoning. We base our rationale on the fact that during our evolutionary history, people easily registered the differences in gender and developed adaptations to preferentially encode the gender dimension. However, our ancestors almost never have encountered people belonging to a different "race" because they primarily traveled on foot and were geographically isolated. Therefore, there could have been no selection for cognitive adaptations designed to encode race in automatic and mandatory fashion. Similarly, we 
view tenure as more influential than education and function because it can be viewed as a manifestation of experience, which has long been valued in human society.

\section{Theoretical Model and Propositions}

We draw on the theory of group diversity profiles and categorization processes in bicultural organizational teams (Thatcher \& Jehn, 1998) to predict the effect of group faultlines on conflict, adjusted for the relative importance of certain demographic characteristics (see Figure 1). In particular, we use the argument that visible characteristics (age, race, and gender) are easily observable and hence, are more accessible than non-visible characteristics (education, tenure, and function) (Tsui, Egan, \& O'Reilly, 1992). Furthermore, the people conceptualize themselves into categories based on the visible characteristics such as age, race, and gender even before any interaction between them occurs (Thatcher \& Jehn, 1998). Once they categorize themselves, the negative process such as in-group favoritism and out-group hostility are likely to emerge (Tajfel \& Turner, 1986). Conflict will eventually arise as a result of these negative categorization processes. This is the reasoning behind our manipulation of the relative weights assigned to visible and non-visible characteristics. Therefore, we propose:

\section{Proposition 1. Group members will be more likely to align along visible characteristics (sex, race, and age), rather than non-visible characteristics (education, tenure, and function). When they do so, the relationship between group faultlines and conflict will be positive and stronger.}

We draw on evolutionary psychological theory (Kurzban \& O'Leary, 2001) to predict the effect of group faultlines weighted by persistence over time within the subgroup of visible demographic characteristics. In particular, we use the argument that older characteristics are more important than the younger characteristics in terms of the historical development of human society. That is to say that older characteristics emerged as a greater source of potential influence within human societies prior to younger characteristics, and thus, carry more weight. We specifically examine gender in 
relation to race. From the evolutionary psychology perspective, individuals activate "primitive" or "primary" dimensions such as race and gender, which our mind encodes automatically across all social contexts. However, the process of encoding or specific cognitive adaptations allowing this automatic processing for gender differs significantly from the process of encoding for race. During our evolutionary history, people easily registered the differences in gender and developed adaptations to preferentially encode the gender dimension. In contrast, our ancestors almost never encountered people belonging to a different "race" because they primarily traveled on foot and were geographically isolated. Therefore, there could have been no selection for cognitive adaptations designed to encode race in automatic and mandatory fashion. We propose that group faultlines that take into account respective weights of visible characteristics based on persistence over time will be better predictors of group conflict.

\section{Proposition 2. Group members will be more likely to align along visible characteristics that are more persistent over time (sex), rather than those that are less persistent (race). When they do so, the relationship between group faultlines and conflict will be positive and stronger.}

We draw on evolutionary psychological theory (Kurzban \& O'Leary, 2001) to predict the effect of group faultlines weighted by persistence over time within the subgroup of nonvisible demographic characteristics. Based on the previous discussion, we argue that tenure will carry more weight than education or function because tenure is a manifestation of experience, which has long been valued in human society. Further, in many traditional societies, function and tenure are related to age, a visible characteristic. As visible characteristics are easily accessible and observed, people are more likely to categorize themselves and create a basis for group faultlines based on age. As tenure and function often accompany age, and age is a visible characteristic carrying more weight than non-visible characteristics (education, tenure and function), we propose that tenure and function will carry greater weight than education. Since formal education is a recent development in society it carries less innate value than experience. From a global perspective, there are many nations where education is still only at a rudimentary level and experience is clearly more valuable. Even in developed, educated societies, however, 
education is often held implicitly subordinate to experience. Tenure is often an antecedent of function. Therefore we propose:

\section{Proposition 3. Group members will be more likely to align along non-visible characteristics that are more persistent over time (tenure), rather than those that are less persistent (education and function). When they do so, the relationship between group faultlines and conflict will be positive and stronger.}

\section{Group Culture and Team Identity}

To further examine the relationship between group faultlines and conflict, we apply a more complex framework and consider the role of contextual variables (Chatman, Polzer, Barsade, \& Neale, 1998; Jehn, Northcraft, \& Neale, 1999). We propose that certain contextual factors will either inflate or deflate the potency of each demographic characteristic in forming group faultlines and resulting in conflict. One of the most often studied moderators in diversity research is group culture (Jehn, 1994; c.f. Williams and O'Reilly, 1998). In this paper, we consider the role of a content-specific, change-focused group culture on the relationship between group faultlines and conflict. We define group culture focused on change as encompassing the group members' beliefs about possibilities for change and innovation in their group. We propose three different effects for the relative importance of group faultlines in relation to conflict.

First, we propose that group culture focused on change reduces anxiety and fear toward uncertainty, which leads to less negative categorization based on visible characteristics. Research on innovation (Bunce \& West, 1995; Scott \& Bruce, 1994) and issue selling (Aschford et al., 1998) suggests that work group culture that supports and encourages change will also facilitate the effective internal channels for the expression and consideration of employee criticism. Since group members are increasingly faced with the uncertainty and anxiety that come with global competition, rapidly changing market environments, organizational downsizing, work-family tensions, and other organizational changes (Pratt, 1992), those channels will provide them with a sense of security and 
reduce the perceived uncertainty. The group members will be less likely to perceive uncertainty as threatening to their relative stability and reliability. This will promote less self-categorization that will lead to less salient differences and, therefore, less chances of forming group faultlines based on group members' visible demographic characteristics.

Proposition 4. Group culture focused on change will moderate the relationship between group faultlines and conflict. When there is a strong group culture focused on change, groups that have faultlines along visible characteristics will have less conflict. In contrast, when there is a weak group culture focused on change, groups that have faultlines along visible characteristics will have more conflict.

In an organizational culture of change, that is organizational focus on opportunities, flexibility and innovation, divergent thinking is likely to be encouraged and rewarded (Flynn, Chatman, Spataro, 2001). Therefore, in mixed gender groups, the perspective of the other is more likely to be heard and/or acted upon. Hence, alignments along gender lines, due to the evolutionary age of gender versus other characteristics, are less likely to occur and result in conflict. (Kurzban, Tooby, \& Cosmides, 2001),

Proposition 5. Group culture focused on change will moderate the relationship between group faultlines and conflict. When there is a strong group culture focused on change, groups that have faultlines amplified by the persistence over time of the subgroup of visible characteristics will have less conflict. In contrast, when there is a weak group culture focused on change, groups that have faultlines amplified by the persistence over time of the subgroup of visible characteristics will have more conflict.

Finally, group culture focused on change can be viewed as an impetus for greater conflict within the group because it creates greater uncertainty as a result of numerous, potentially conflicting opportunities and perspectives. From this uncertainty, usually one decision must be made, which requires the consent of group members. Since those with the greatest tenure (or experience) are likely to be the older and more conservative members 
of the group, arriving at this decision will create strong group faultlines that cause more conflict. Additionally we use the integrative complexity argument to propose that the status of education will be given more importance in creating group faultlines that cause conflict when the organizational culture focused on change is strong. Education could be viewed as a function of differences in status that are often associated with conflict and inferior group processes and cooperation (Jackson, Brett, Sessa, Cooper, Julin, and Peyronnin, 1991; Thomas, 1995).

\section{Proposition 6. Group culture focused on change will moderate the relationship between group faultlines and conflict. When there is a strong group culture focused on change, groups that have faultlines amplified by the persistence over time of the subgroup of non-visible characteristics will have more conflict. In contrast, when there is a weak group culture focused on change, groups that have faultlines amplified by the persistence over time of the subgroup of non-visible characteristics will have less conflict.}

According to Lau and Murnighan (1998), faultlines can lead to salient subgroups that then become a basis for social identification and categorization. Because individuals have multiple identities, the salience of a particular identity depends on the context where individuals operate (Hogg \& Terry, 2000). Team identity can be considered as a context variable or another potential moderator of the group faultlines-conflict link. Team identity refers to an individual's sense that his or her team has a unified identity and reflects a sense of entitativity, or a common perception of group cohesiveness (definition adapted from Early \& Mosakowski, 2000). We argue that team identity will either inflate or deflate the potency of each demographic characteristic on conflict. Based on social identity and social categorization theories (Tajfel \& Turner, 1986), we propose that groups that have faultlines along visible characteristics, will have less inter-subgroup conflict when group members strongly identify themselves as a single team. In particular, we argue, consistent with Thatcher and Jehn's (1998) theory of intercultural interaction within groups, that when the group develops a strong sense of group identity, the group members are less likely to categorize themselves based on the visible or "primary" characteristics (race, age, gender) and more likely to conceptualize themselves as 
members of this work group. That is, group faultlines will have less impact on conflict when there is a strong team identity. Furthermore, based on the discussion above, we argue that groups that have faultlines amplified by the persistence over time of the subgroup of visible characteristics or non-visible characteristics will also less likely to form group faultines that cause conflict when group members have a strong team identity. Therefore, we propose that:

Proposition 7. Team identity will moderate the relationship between group faultlines and conflict. When there is a strong team identity, groups that have faultlines along visible characteristics will have less conflict. In contrast, when there is a weak team identity, groups that have faultlines along visible characteristics will have more conflict.

Proposition 8. Team identity will moderate the relationship between group faultlines and conflict. When there is a strong team identity, groups that have faultlines amplified by the persistence over time of the subgroup of visible characteristics will have less conflict. In contrast, when there is a weak team identity, groups that have faultlines amplified by the persistence over time of the subgroup of visible characteristics will have more conflict.

Proposition 9. Team identity will moderate the relationship between group faultlines and conflict. When there is a strong team identity, groups that have faultlines amplified by the persistence over time of the subgroup of nonvisible characteristics will have less conflict. In contrast, when there is a weak team identity, groups that have faultlines amplified by the persistence over time of the subgroup of non-visible characteristics will have more conflict. 


\section{References}

Chatman, J., Polzer, J., Barsade, S. \& Neale, M. 1998. Being Different Yet Feeling Similar: The Influence of Demographic Composition and Organizational Culture on Work Processes and Outcomes. Administrative Science Quarterly, 43: 749-780.

Hagendoorn, L., Drogendijk, R., Tumanov, S., \& Hraba, J. 1998. Inter-ethnic preferences and ethnic hierarchies in the Former Soviet Union. International Journal of Intercultural Relations, 22: 283-503.

Jehn, K. 1994. Enhancing effectiveness: An investigation of advantages and disadvantages of value-based intragroup conflict. The International Journal of Conflict Management, 5 (3): 223-238.

Jehn, K., Northcraft, G. \& Neale, M. 1999. Why Differences Make a Difference: A Field Study of Diversity, Conflict, and Performance in Workgroups. Administrative Science Quarterly, 44: 741-763.

Kurzban, R. \& Leary, M. 2001. Evolutionary origins of stigmatization: The Functions of Social Exclusion. Psychological Bulletin, 127 (2): 187-208.

Kurzban, R., Tooby, J., \& Cosmides, L. 2001 Can race be erased? Coalitional computation and social categorization. PNAS, 98 (26): 15387-15392.

Lau, D. \& Murnighan, J.K. 1998. Demographic diversity and faultlines: The compositional dynamics of organizational groups. Academy of Management Review, 23 (2): $325-340$.

Mullick, R., \& Hraba, J. 2001. Ethnic attitudes in Pakistan. International Journal of Intercultural Relations, 25 (2): 165-179.

Sidanius, S., \& Pratto, F. 1999. Social dominance: An intergroup theory of social hierarchy and oppression. New York: Cambridge University Press. 
Tajfel, H. \& Turner, J.C. 1986. The social identity theory of intergroup behavior. In Worchel \& Austin (Eds.), Psychology of intergroup relations ( $2^{\text {nd }}$ ed., pp. 7-24). Chicago: Nelson-Hall.

Thatcher, S. \& Jehn, K. 1998. A Model of group diversity profiles and categorization processes in bicultural organizational teams. Research on Managing Groups and Teams, 1: $1-20$.

Tsui, A., Egan, T., O’Reilly, C. 1992. Being different: Relational demography and organizational attachment. Administrative Science Quarterly, 37 (4): 549-577. 
Figure 1. Theoretical Model.

froultlines:

-visible vs. non visible

-visible: sex vs. race

-non-visible: tenure vs. education

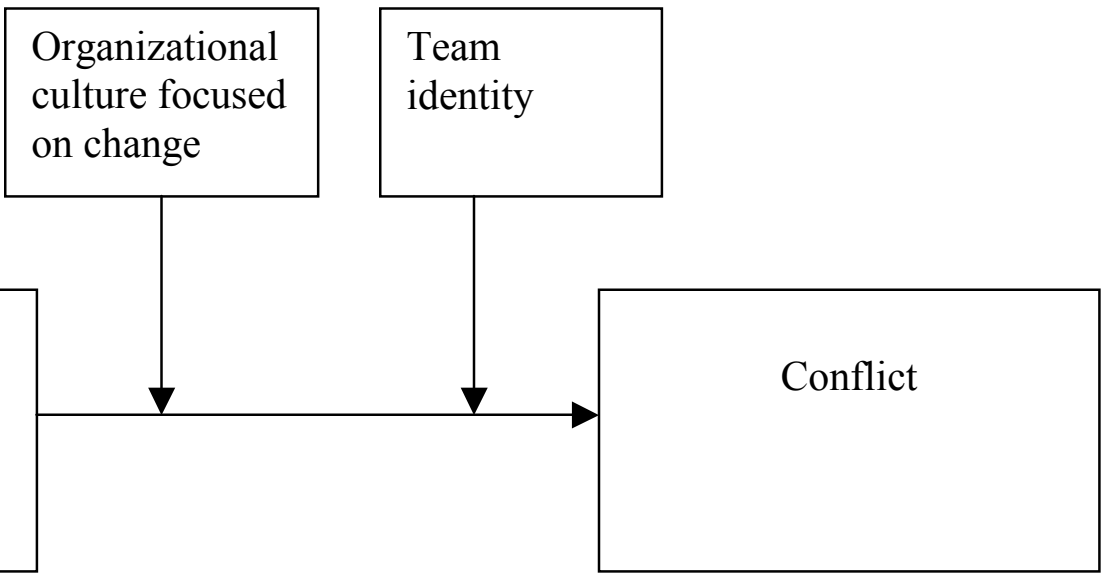

